\title{
HYDROLOGICAL AND HYDROGEOLOGICAL CHARACTERISTICS OF THE PLATFORM KARST (ZEMO IMERETI PLATEAU, GEORGIA)
}

\section{Zaza Lezhava}

Vakhushti Bagrationi Institute of Geography, Iv. Java- khishvili Tbilisi State University, 6. Tamarashvili Street, Tbilisi, 0177, Georgia,Zazalezhava@gmail.com

\section{Nana Bolashvili}

Vakhushti Bagrationi Institute of Geography, Iv. Java- khishvili Tbilisi State University, 6. Tamarashvili Street, Tbilisi, 0177, Georgia,nana.bolashvili@gmail.com

\section{Kukuri Tsikarishvili}

Vakhushti Bagrationi Institute of Geography, Iv. Java- khishvili Tbilisi State University, 6. Tamarashvili Street, Tbilisi, 0177, Georgia, kukuritsikarishvili@ymail.com

\section{Lasha Asanidze}

Vakhushti Bagrationi Institute of Geography, Iv. Java- khishvili Tbilisi State University, 6. Tamarashvili Street, Tbilisi, 0177, Georgia, asanidze.lasha@yahoo.com

\section{Nino Chikhradze}

Vakhushti Bagrationi Institute of Geography, Iv. Java- khishvili Tbilisi State University, 6. Tamarashvili Street, Tbilisi, 0177, Georgia

School of Natural Sciences and Engineering, Ilia State University. Kakutsa Cholokashvili Ave 3/5, Tbilisi 0162, Georgia,nchikhradze@yahoo.com

\begin{abstract}
The article discusses the hydrological and hydrogeological characteristics of the platform karst of Zemo Imereti plateau. The structural plateau of Zemo Imereti is the part of the intermountain plain karst zone of Georgia and one of the interesting parts of the karst relief development. The above mentioned karst region includes the easternmost part of western Georgia, which is characterized by peculiar natural conditions (relief, tectonics, climate, surface and underground streams) and represents one of the significant platform karst regions in the Caucasus. On the basis of the cartographic materials analysis and borehole data, the general scheme of hydrogeological situation of the Zemo Imereti structural plateau (two hydrogeological basins were defined) was created as confirmed by experiments. In addition, it was identified that underground karst water flowing from the periphery to the center determines sedimentation together with the broken dislocations within the frame of the structural plateau. The study found that within the Chiatura structural plateau the joint karst hydrogeological system (with enough dynamic water resources) has been established, which mainly is unloaded in sources of Ghrudo vaucluse and the surrounding area
\end{abstract}

(local erosion basis). Ghrudo hydrogeological system and Chiatura structural plateau are characterized by the systems of isolated karst-fissure waters with different hypsometric location and orientation. Therefore, based on these studies, it could be said that in karst areas the structural features can define the characteristic of groundwater circulation, but karst age can also make a significant adjustment.

\section{Introduction}

Conflicting views on underground karst water circulation has been formed in the very beginning of the systematic study of the karst. Certain Western European researchers argued that there should be a common underground water level in the karst districts (Grund, 1903). In contrast, others gave advantage to the theories of the isolated systems (Martel, 1894; Knebel, 1906; Katzer, 1909). In this discussion, the results of which still did not lose their importance, A. Kruber (1915), V. Varsanofieva (1915) and other researchers actively participated. Later the mentioned issues were generalized based on the rich actual materials in the works of the former Soviet researchers as well (D. Sokolov, 1962; Z. Tintilozov, 1976 and G. Gigineishvili, 1973). 
There were attempts to explain these opposing theories by (1) structural and geological conditions; the overall level of underground waters are related to the platform conditions and the isolated ones - to the geosynclinal conditions (G. Gigineishvili, D. Tabidze, 1975; G. Tintilozov, 1976); (2) different capacities of karsting rocks; the overall level of underground waters are related to the "thin" karst and the isolated ones - to the "deep" karsts (Gèze, 1965); and (3) different stages of karst development; the overall level of underground waters are related to the "mature" and "old" stages and the isolated ones to the "young" stage (Kruber, 1915).

In the limestone belt of the western Georgia, which is a part of the Caucasus orogenic section, the isolated underground basins (Bzipi and Arabika limestone massifs) are identified by the Georgian researchers on the basis of fundamental researches (Kiknadze, et al., 1973; Maruashvili, et al., 1971; Tintilozov, 1976). In addition, in the easternmost part of the mentioned karst zone, which is known as the Zemo Imereti karst plateau, there is an assumption of the existence of the common level of the karst waters (Gigineishvili, et al., 1975). This point of view gained precision by the methods and experiments used during the study.

\section{Description of the study area and materials}

Zemo Imereti plateau is a compound part of the limestone belt and is critical to the development of the karst relief in Georgia's intermountain plain. The aforementioned region includes the easternmost part of the limestone belt of the western Georgia, which is characterized by the peculiar natural conditions (relief, tectonics, climate, surface and underground flows) and is one of the most important regions of the plate karst in the Great Caucasus (Figure 1).

The boundary of the Zemo Imereti karst region lays through the Cretaceous limestones surface contact line with the formations of older age (Bajocian porphyritic series to the north and east, and to the south and west the Middle Paleozoic granitoids). Cretaceous limestones base is created by the Paleozoic formations, which suffered denudation during the Upper Jurassic and partially during the Lower Cretaceous periods, resulting in formation of the Likhi peneplain (Maruashvili, et al., 1971).

The presence of the solid platform with a peneplained surface caused a laying character (still, almost horizontal or slightly inclined layers laying) of the Mesozoic-Cainozoic cover on it, which is represented by the Valangin-

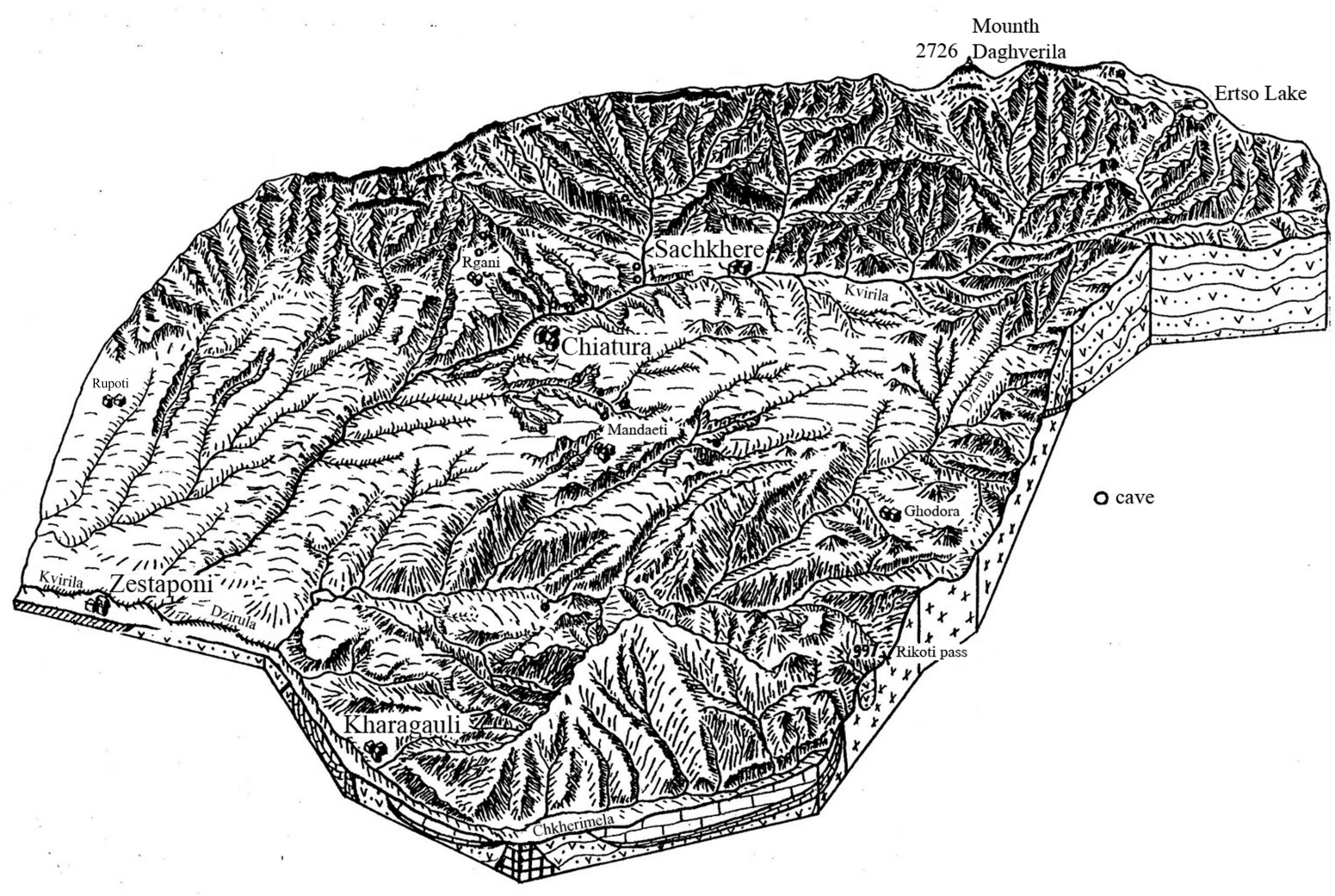

Figure 1. Block-Diagram of the Zemo Imereti Plateau and its Surroundings 
ian - Hauterivian, Barremian and Turonian-Danish limestones, Tertiary clays and sandstones. Sedimentation of the mentioned deposits occurred in the platform conditions and in connection with it their total capacity does not exceed 500-550 meters.

Morphologically the Zemo Imereti karst region is a structural plateau, fragmented down to the $150-250 \mathrm{~m}$ depth. The Kvirila River valley divides the Zemo Imereti Plateau into the two parts - of northern (the right side of the Kvirila River with the area of 116 sq. $\mathrm{km}$ ) and southern (the left side of the Kvirila River with the area of $208 \mathrm{sq} . \mathrm{km}$ ). The latter is represented in the form of a single plateau, the surface of which is built by a powerful Tertiary clay layers. The clay layers cover limestones and hinder the development of karst. Morphologically the northern part looks somewhat complex. Its oncefragmented plateau surface is separated by the narrow gorges of the Kvirila River's right tributaries: Jruchula, Nekrisa, Bogiristskali, Tabagrebistskali, Rganisghele and Katskhura, among which are erected morphologically separated plateaus: Bajiti, Darkveti, Mghvimevi, Rgani and Katskhi (their absolute heights are 550-650 $\mathrm{m}$ above mean sea level). Turonian-Danish limestones, which build the surfaces of the mentioned plateaus, are covered with the clays and sandstones containing the
Tertiary manganese ore of little capacity over the small area. The slopes of the mentioned plateaus are steep; their relative heights are gradually decreased from the $230 \mathrm{~m}$ to $100 \mathrm{~m}$ from the west to the east along the Kvirila River gorge. Dense network of water absorption of the relief on the structural plateau of Zemo Imereti, surface and underground karst forms, etc. indicate the intensity of karst development.

Kvirila River and its tributaries do not cross the limestone cover above the city of Chiatura up to its base - the Likhi peneplain. Therefore, all morphologically isolated plateaus to the both sides of the Kvirila River have a common limestone base, which creates the favorable conditions for the formation of the common level of the underground waters in case of proper structural conditions.

\section{Research goals, methods and results}

We have carried out a karst-hydrological and hydrogeological works in order: 1) to identify the peculiarities of the underground karst waters laying conditions, movement and their determining factors; and 2) to solve certain practical issues within the Zemo Imereti structural plateau (the underground karst waters are widely used in the water supply of the city of Chiatura and the villages

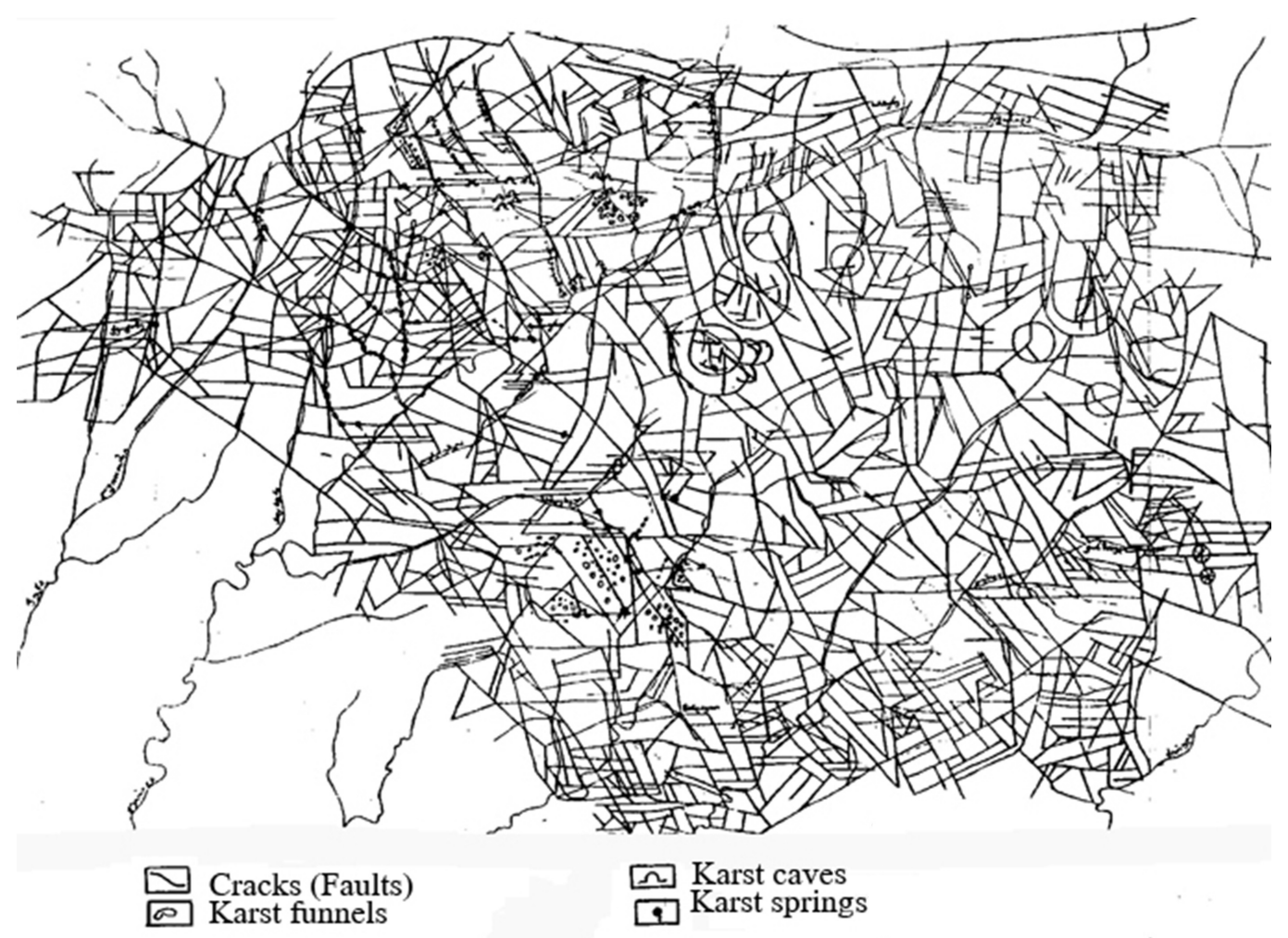

Figure 2. Fault Dislocation Scheme of the Chiatura Structural Plateau (Compiled by decoding of the aerial images) 


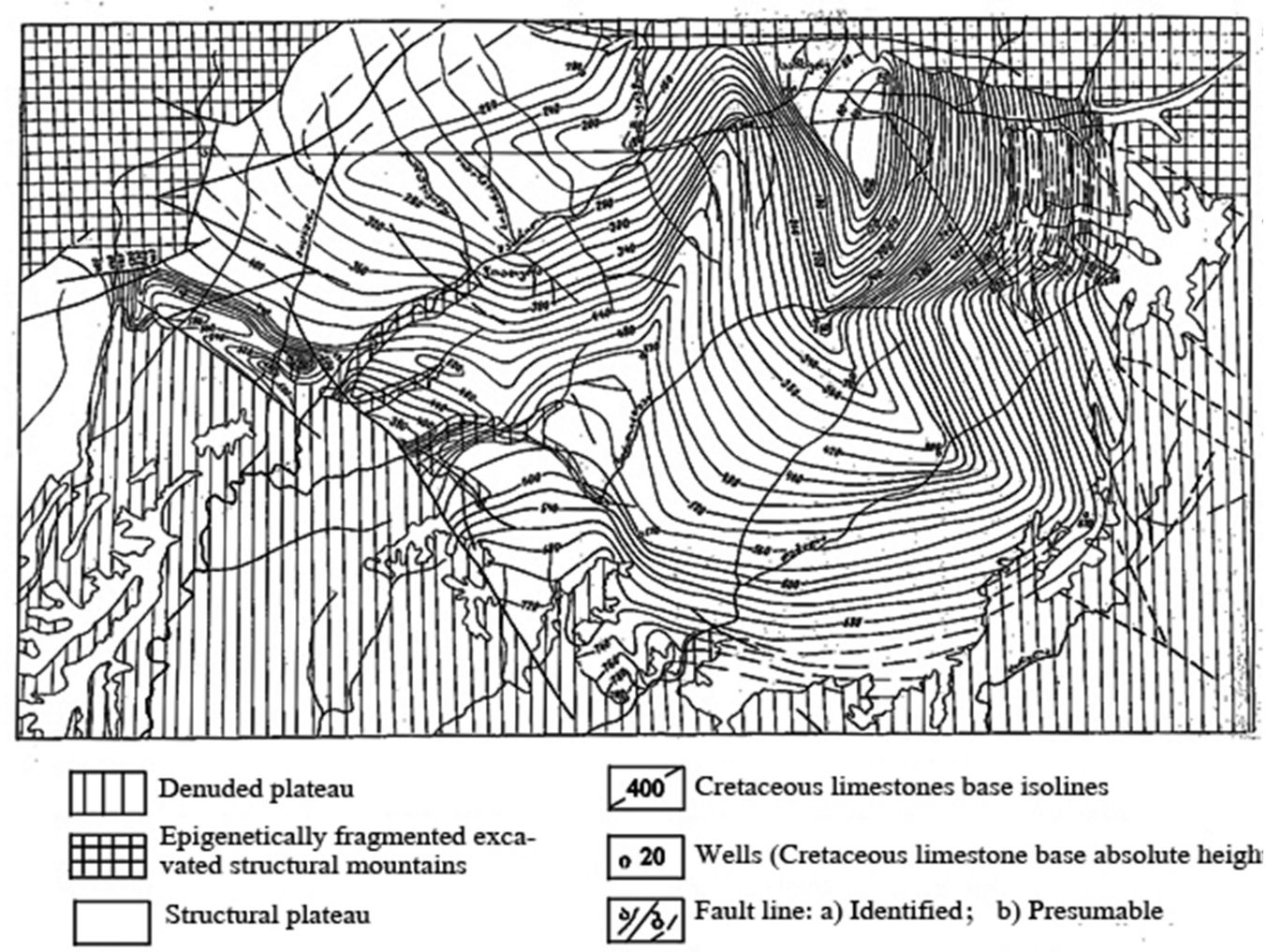

Figure 3. Geological Section of the Drilling Wells in the Chiatura Structural Plateau

located near the plateau. Periodic pollution of these waters causes a number of delays in water supply system. In this regard, it was necessary to identify the water pollution centers, their movement lines, etc.). We used driller's well logs and geological sections data, aerial images structural decoding and electrometric search methods, as well as the groundwater tracing experiments. On the basis of the conducted studies we obtained the results of interesting scientific and practical value.

For advanced study of the tectonic setting (faults, shearing, tectonic fractures) in Zemo Imereti (Chiatura) structural plateau we carried out structural decoding of the aerial images of the territory. It enabled us to draft a detailed schematic of a fault dislocation and to identify the regularities of karst forms distribution. Decoding has revealed a dense network of previously unknown faults and fractures of different direction (Figure 2).

We determined that the tectonic shearings and fractures control the underground waters absorption, movement and discharge. Fractures of sublatitudinal and submeridional direction are particularly distinguished, to the sectors of intersection of which are related the majority of surface and underground karst forms and the karst processes (karst forming) intensity in general.
Borehole data (Figure 3) and cartographic material (geological profiles, etc.) analysis were basis for the topographic scheme of the limestone (Mesozoic-Cenozoic) bed, where the buried morpostructures were identified (Figure 4).

Analysis of the limestone bed topography and buried morphostructure clearly shows that to the east of the structural and denudation plateau dividing shearing submergence of karsting rock beds starts to the north-east or to the Sachkhere syncline mold. It seems that the conditions of their occurrence and inclination stipulate the groundwater movement and direction in the study area (the role of the shearing and fractures is considerable as well). This situation completely changes our opinions and views about the underground water discharge centers within the plateau. According to these views, the water discharge was assumed to be in the western part of the Kvirila River canyon gorge composed of limestones and they thought it was possible for that part of it was flowing into the Kolkheti artesian hydrogeological basin.

Based on the Mesozoic-Cenozoic bed and fault dislocations' (decoding) schemes we compiled the general scheme of the structural plateau's hydrological setting. In the scheme, we singled out the two hydrogeological 


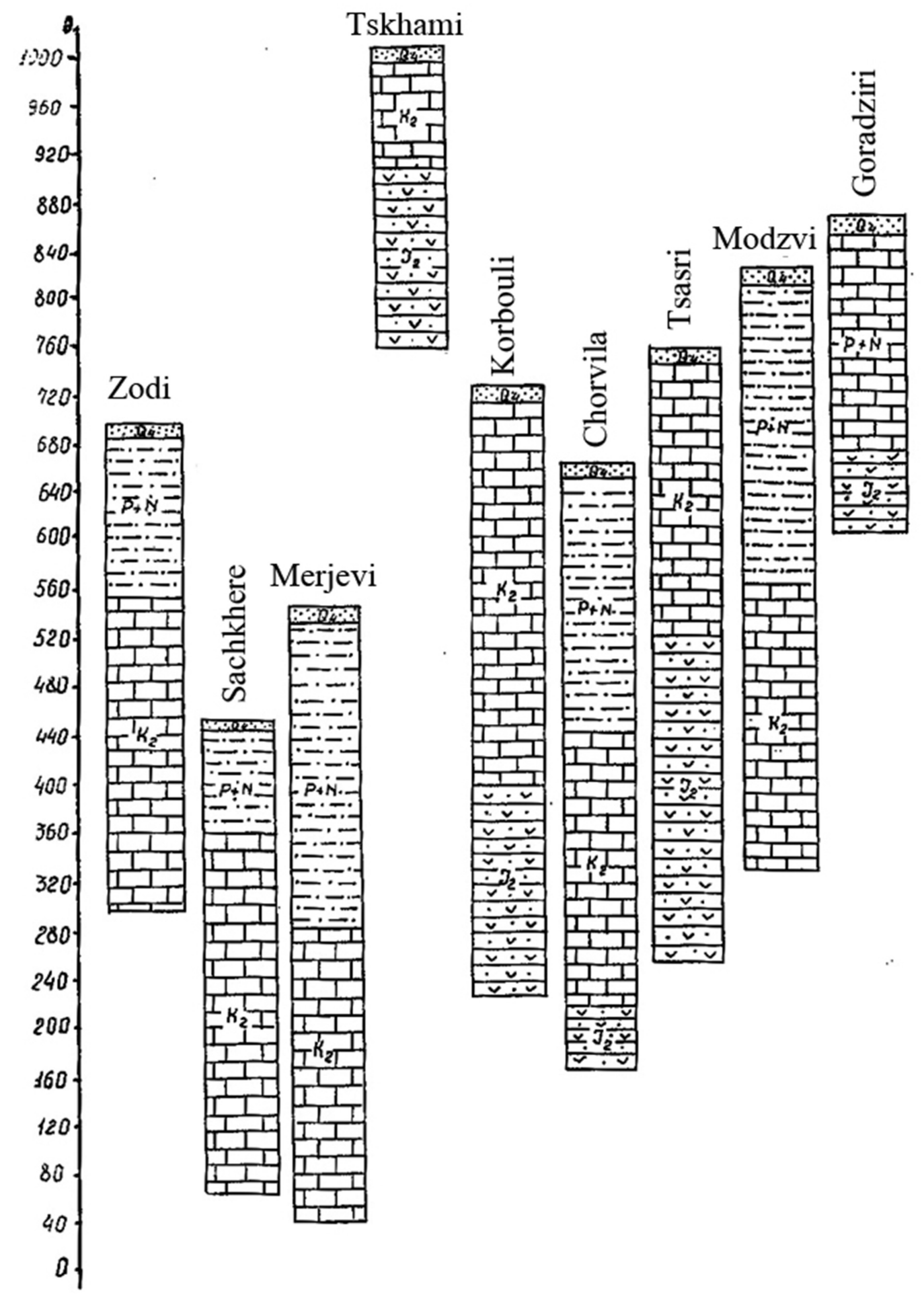

Figure 4. Topography of the Tectonic Upper Floor (Mesozoic-Cenozoic) Underlayer of the Chiatura Structural Plateau 


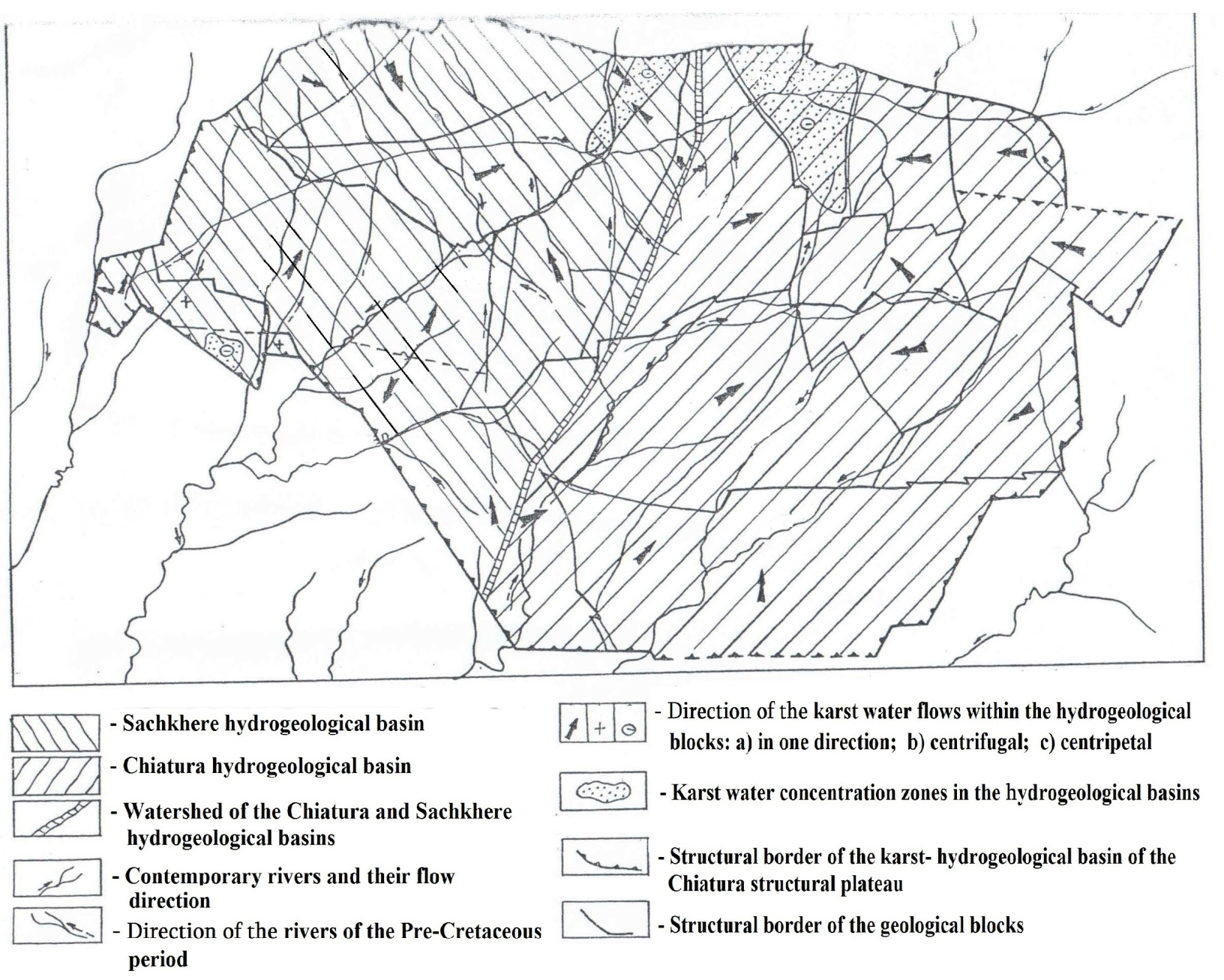

Figure 5. Paleomorphostructural Zoning of the Submerged Block of the Chiatura Structural Plateau (By the General Scheme of the Hydrogeological Situation)

basins with the water storage area or the vast water reservoirs, which are the prospective areas for receiving the drinking water (Figure 5).

During distinguishing the separate blocks by the fault lines the following fact was taken into account: the crystalline basement is upraised with the different heights within the Zemo Imereti structural plateau and the cross section and capacity of the sedimentary cover is also different.

In addition, the hotbed structures on forming the mechanical strain often play a role of the tectonic stamp and they control the faults. It seems that the directions of the underground karst water movement is different inside the individual blocks singled out by the faults, though it is possible that there is a water cycle among the blocks as well. Directions of the underground karst water movement within the individual blocks and within the hydrological basins in general are confirmed by the dye tracing experiments carried out by us (Figure 6).

In addition, in many cases the dyed water crossed the single plateaus and the river beds dividing them from the bottom and was fixed in the springs flowing out in the Kvirila River gorge. It should be noted that the dye tracing experiments were conducted in conditions where the underground waters were at different levels, which showed interesting results. Namely, in one case, the water was spread over the area and it came out simultaneously through the several karst springs. In another case, a number of isolated systems were observed, which are connected to each other by tunnels or narrow fracture systems; they are located at different heights and it seems the water cycle takes place during periods of high water levels. 


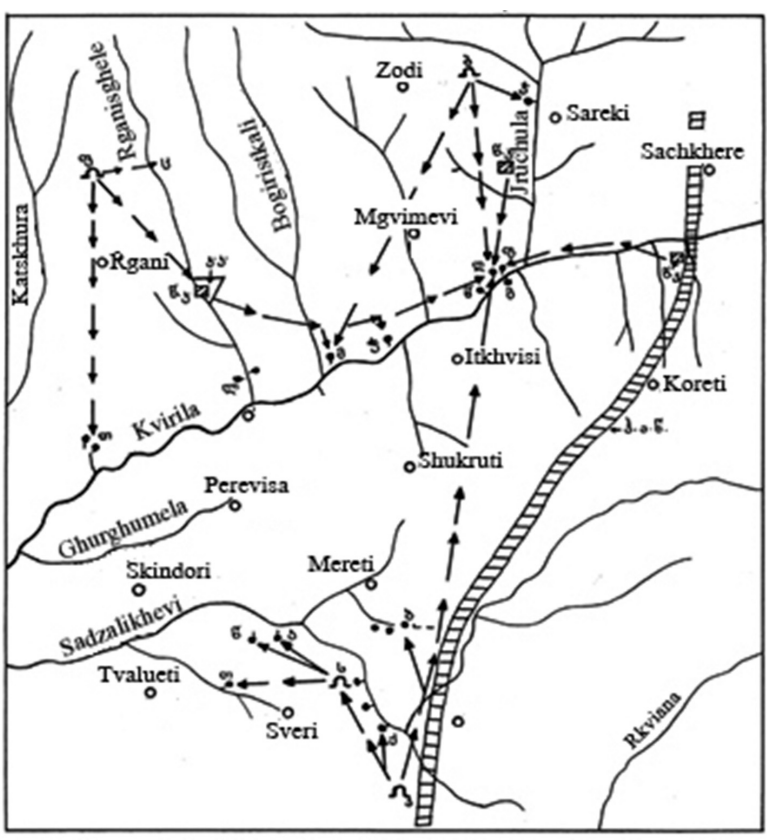

Figure 6. The Groundwater Stream Movement Scheme Obtained by the dye tracing experiments carried out in the Chiatura Structural Plateau.

Thus, for the first time it has been shown that within the Zemo Imereti (c. Chiatura) structural plateau the movement directions of the underground flows are mainly determined by the structural features, namely: total submergence of the karsting rocks from the periphery to the center, as well as shearing dislocations, which greatly control the groundwater flow absorption and their movement ways. In addition it was identified that the Zemo Imereti structural plateau's underground karst water regime is characterized both by the streams with common level (tracings painted widely open water) and by separate streams as well, which makes doubtful the recognition of absolute reality of the platform type. As a result of the dye tracing experiments the boundaries of the feeding basins of Ghurdo and other springs have been specified. It seems that within the mentioned boundaries the common karst-hydrogeological system (with the dynamic water resources) is formed, the waters of which are discharged mostly the Ghurdo and the springs running in its surroundings. The fact is of great practical importance because it is possible the contaminated waters to be flowed into the Chiatura water supply system from any karsted place within the mentioned boundaries, and which should be considered during the anthropogenic impact on the environment. Based on the dye tracing experiment results, the recommendations have been pre- pared, which included the removal of some of the karst waters involved in the water supply system.

\section{Discussion and Conclusion}

Thus, the morphostructures of the Chiatura structural plateau (western Georgia) are presented as a mosaic of different sizes elevated or lowered blocks, which were emerged during the evolution process of the regional and local submeridional and sublatitudinal shearings. Most of the old faults undergo the transformation and rejuvenation along with the tectonic movements, which is promoted by the intense karst processes.

The study area is located within the vertical (epeirogenetic) uplifting zone. Contemporary geomorphological cycle (erosion, karst and other forms origination and development) has begun in the Post-Miocene in the Zemo Imereti plateau and its neighboring regions. The PostMiocene tectogenesis was strong in the Caucasus folded zone while the activity in the Zemo Imereti platform was expressed mainly in vertical (epeirogenetic) uplifting, which was accompanied by a small local faults and wave folds. The last manifestation of magmatic activity would have occurred in the same period which emerged the Goradziri, Perevisa and other laccolite-extrusions; also, the central type structures (volcanic apparatus or intrusives of isomeric forms) in the Pre-Cretaceous substrate which control the faults and play the tectonic stamp role (Dvalashvili, et al., 2014).

The Post-Miocene period's uplifting of the study area is continuing even today. Neotectonic movements obviously played a considerable role in the evolution of the erosion fragmentation and karst genesis processes and fissure-karst water vertical hydrodynamic zones. Along with the uplifting tectonic movements, the rivers have generated deep canyon gorges (tectonic fractures played the important role in the canyon gorges genesis and the identification of the river direction), which created favorable conditions for deep-water circulation.

The wide spreading of the disjunctive dislocations in the Zemo Imereti plateau determined the formation of the independent streams, the common basis of which is the Kvirila River. In addition, at present stage the single karst caves and vaucluse springs canals which were formed still at early stages, were combined into the Ghurdo common hydrogeological system (Figure 7). It is still inaccessible, though, the development of the hollows in its basins is intense.

It seems that the ascending tectonic movements were not continuous, but had periods of slowdown, as evidenced by the level distribution of the caves in the Kvirila River 
and Jruchula River gorges. The caves of different evolution stages are placed in 4 to 5 levels (Lezhava, et al. 1992).

In addition, it appears that the slowdown epochs were marked by a short duration, to which indicates the widespread of the tunnel (or hole) type of undeveloped caves and poorly (in addition, fragmented) expressed terrace steps in the river gorges. Comparison of the relative heights of the cave levels and terrace steps with the absolute heights of the cave entrances and karst springs exits allows for the assumption that the ascending tectonic movements' slowdown (delay) epoch would be at least $4 \mathrm{t}-5$.

\section{References}

Dvalashvili GB, Lejava ZI. 2014. On a new form of denudation-tectonic forms of the relief. The 3rd International Scientific and Practical Conference. Strategic Solutions of the Information Development of Economy, Society and Business. Reports Abstracts, 12-14 Feb. Ukraine, Rovno. (In Russian language).

Gèze B. 1965. La Speleologie Scietibique. Paris, France. Gigigeishvili GN. 1973. Karst waters of the mountain areas. Coll: Caves of Georgia, 5. (In Russian language).

Gigineishvili GN, Tabidze DD. 1975. Uniform level of groundwater in platform karst environment of western Georgia (Dzirula karst region). Bulletin of the Georgian Academy of Sciences 77 (3). (In Russian language).

Grund A. 1903. Studien aus Westbosnien. Leipzig. Geogr. Abhand 1 (7): 3.

Katzer F. 1909. Karst und karst hydrographie. Zur Kunde der Balkanhaldinsel. Sarajevo (BA).

Kiknadze TZ, Tabidze DD. 1973. About groundwater basins of karst waters of the Arabica limestone massif. Coll: The Caves of Georgia 5. Tbilisi (GE). (In Russian language).

Knebel W. 1906. Höhlenkunde mit Berücksichtigung der Karstphänomene. Braunschweig.

Kruber AA. 1915. Karst region of the Mountainous Crimea. M. (In Russian language).

Lezhava Z, Tintilozov Z, Kipiani Sh. 1992. Conditions for karst caves genesis in the Zemo Imereti plateau. Vakhushti Bagrationi Institute of Geography. Final Scientific Session. Tbilisi, Georgia. (In Georgian language).

Martel EA. 1894. Les Abimes. Paris, France.

Maruashvili LI, Tintilozov ZK. 1971. In book: "Geomorphology of Georgia.” Tbilisi (GE). p. 466-478. (In Russian language).
Sokolov DS. 1962. The main conditions of karst development. Gosgeoltekhizdat, M. (In Russian language).

Tintilozov ZK. 1976. Karst caves of Georgia (morphological analysis). Tbilisi (GE). (In Russian language).

Varsanofieva V A. 1915. Karst phenomena in the northern part of the Ufa plateau. Zemlevedenie 22 (4). (In Russian language). 